\title{
Overall energy requisite and quality feature of industrial paddy drying
}

\begin{abstract}
Energy consumption and rice quality are the main concerns of millers and must be assessed to ascertain suitable industrial drying strategy. In this article, industrial paddy drying methods as usually practiced in the BERNAS paddy drying complexes of Malaysia have been evaluated. The analysis showed that the specific electrical and thermal energy consumption varied between $16.19 \mathrm{kWh}$ to $22.07 \mathrm{kWh}$ and $787.22 \mathrm{MJ}$ to $1015.32 \mathrm{MJ}$, respectively, in single-stage paddy drying (SSPD) using an inclined bed dryer (IBD) to dry each tonne of freshly harvested paddy with average moisture content of $23.35 \pm 0.86 \%$ wb. On the other hand, the energy consumptions for two-stage paddy drying (TSPD) with a fluidized bed dryer (FBD) followed by IBD were $21.37 \mathrm{kWh} / \mathrm{t}$ to $30.69 \mathrm{kWh} / \mathrm{t}$ and $666.81 \mathrm{MJ} / \mathrm{t}$ to $1083.42 \mathrm{MJ} / \mathrm{t}$, respectively. SSPD at $35-39^{\circ} \mathrm{C}$ and TSPD using FBD at $120^{\circ} \mathrm{C}$ as the first stage, followed by IBD as the second stage at lower temperature of $35-39^{\circ} \mathrm{C}$ yielded $2-3.6 \%$ higher head rice yield than paddy-dried by a single stage with IBD using comparatively higher temperature of $40-44^{\circ} \mathrm{C}$. Therefore, IBD is recommended to be operated using a temperature of $35-39^{\circ} \mathrm{C}$ both in single-stage drying and second-stage drying of paddy after fluidized bed drying to obtain quality rice.
\end{abstract}

Keyword: Energy requisite; Fluidized bed dryer; Inclined bed dryer; Industrial paddy drying; Rice quality 